\title{
Commercial Translation Error Analysis: A Case Study of Iranian Products
}

\author{
Mitra Eftekhar ${ }^{1}$, Peyman Nouraey $^{2, *}$ \\ ${ }^{1}$ Department of Translation Studies, University of Isfahan ,Iran \\ ${ }^{2}$ Department of Translation Studies, Fars Science and research Branch, Islamic Azad University, Iran \\ *Corresponding Author: peymannouraey@gmail.com
}

Copyright $(2013$ Horizon Research Publishing All rights reserved.

\begin{abstract}
Within the realm of Translation Studies, comparative studies hold a great deal of importance. Likewise, Translation Quality Assessment is treated as a fast-growing sub-field in Translation Studies, focusing on the inter-relationships between the source and the target texts. These inter-relationships involve the lexis, grammar, syntax, and semantics of both texts. Unlike sentences in isolation, texts are context-bound and thus a distinction between text and sentence is made. The present work was motivated by the researchers' wish to reveal the nature of the English translations of Iranian product labels by investigating the errors occurred on these labels. To pursue this purpose, a corpus of three-hundred translated home appliances labels designed for Iranian products manufactured between 2010 and 2012 were collected through purposive sampling and then subjected to error analysis.Using Keshavarz' (1993) model of error analysis, each and every sample was placed under its possible category of errors. The results of the analyses indicated that over half of the total number of the labels under study were erroneous ones, either 'grammatically', 'semantically' or 'pragmatically'. The results also pointed out that grammatical errors held the highest frequency among the other types of errors presented by Keshavarz (1993), holding fifty percent of the total errors occurred.
\end{abstract}

Keywords Label Translation, Error Analysis, Translation Quality Assessment, Commercial Translation, Keshavarz' (1993) Model.

\section{Introduction}

The advent of the $21^{\text {st }}$ century has coincided with globalization in scientific, technical and economic activities on an international scale, which has magnified the role of English language in the international communications. There is a need for an internationally accepted language. English language has attained that status; it is used in global business for transactions in goods and services, technical specifications, financial reports and other purposes among native and non-native speakers through the world.In order to achieve better and more effective results in international trade, the authorities in non-native companies should be proficient in using business English(Brown 1994).A business text,in addition to being acceptable from the same syntactic viewpoints, should also be accepted in terms of socio cultural values.

The preset study was carried out to reveal the nature of English translations of Iranian product labels. To do so, it focused on an error analysis investigation of translated product labels appearing on the following error analysis, emphasizing the significance of errors in learner's inter-language system (Brown, 2000). As Taylor (1975) points out, researchers are interested in errors because they are believed to contain valuable information about the strategies that people use to acquire language (as cited in Brown, 1994).

Error analysis has two objects: one theoretical and another applied (Corder, 1971). The theoretical object serves elucidate what and how a learner learns when he studies a second language and the applied object serves to enable the learner to learn more efficiently by exploiting our knowledge of his dialect for pedagogical purposes.

\section{Literature on Sources of Errors}

Since the emergence of Translation Studies as a nascent academic field of science (Munday, 2008), there has been a growing interest in different models and frameworks of assessing the quality of a translated piece of work. According to Scriven (1993, p.1), evaluation is meant to be "the determination of merit, worth or significance". To put it another way, it would be the main purpose of Translation Quality Assessment (TQA) to label a translation a "weak" or a "good" one. As Williams (2005, p.2) believes, TQA could be "qualitative or quantitative, just like evaluation in the broad sense: it can be based on mathematical or statistical measurements or on reader response, interviews and questionnaires." 
Assessment of a translated text's quality should be based on a definable,applicable, and testable model which, in turn, should be based on acomprehensive theory of translation.Current models for translation emphasize one aspect against other aspects. For instance, the grammatical model focuses on the linguistic aspect of translation (Barghout, 1990).The cultural model, on the other hand, highlights the communicative aspect whereas the interpretive model concentrates on the pragmatic aspect of translation. Such artificial compartmentalization is alien to the nature of translation. As a process translation, in fact,involves the integrated synthesis of the above aspects (ibid.).

A lot of sources of errors have been introduced by several innovative theorists up to the present day (e.g., Williams 2005, Waddington 2001, Hurtado 1995, etc.). In the following section the primary causes of errors will be reviewed:

a) Inter-lingual/transfer errors attributed to the native language (NL). These are inter-lingual errors when the learners L1 habits lead in interference or preventions from acquiring the pattern and rules of the second language (Corder, 1971).

b) Interference errors(or negative transfer) resulting from the negative influence of the mother language on the performance of the target language learner (Lado, 1964).

c) Intra-lingual/ developmental errors attributed to the language being learned, inadequate of the native language.

According to Selinker (1972) there might be five possible sources of errors while dealing with the assessment of a translated piece of work. These include:

1) Language transfer,

2) Transfer of training,

3) Strategies of second language learning,

4) Strategies of second language communication, and

5) Overgeneralization of the linguistic material.

\section{Some Models on Error Analysis}

During the history of translation, many attempts have been made to establish a framework for evaluating the quality of a translation. TQA studies, according to House (1997), can be divided into three major categories:

1) Pre-linguistic studies, in which subjective and not-so-much clear statements, regarding the quality of a translated work, are the major trend.

2) Psycholinguistic studies, in which translation quality is judged in terms of the effect a translated piece of work should have on the readership.

3) Source-text based studies, which attempt to build linguistic criteria in order to account for both the source text and the target text.

Corder (1967) defines a model for error analysis which includes three strategies:

a) Data collection: recognition of idiosyncrasies,

b) Description: accounting for idiosyncrasies dialect, and c) Explanation (i.e., the ultimate object of error analysis). Brown (1994) and Ellis (1994) elaborated on this model, Ellis (ibid.) gave practical advice and provided clear examples of how to identify and analyze learners' errors. Accordingly, the initial step requires the selection of a corpus of language followed by the identification of errors. The errors are then classified. The next step after giving a grammatical analysis of each errors, demands an explanation of different types of errors.

Gass and Selinker (1994) identified six steps followed in conducting an error analysis. These included 'collecting data', 'identifying errors', 'classifying errors', 'quantifying errors', 'analyzing sources of error', and 'remediating for errors.'

Searching into the literature, there have been also pragmatic models presented by Koller (1979/1989). Williams (2005) dividedTQA Models into two main types including 1) models with a quantitative dimension and 2) non-quantitative, text-logical models, such as Nord (1991) and House's models of TQA (1997).

Hurtado (1995) presented a detailed framework as related to translation quality assessment. This model is based on error analysis and begins with careful comparisons made between the elements of the source and the target language. Then, each type of shortcoming faced during the process of translation is given a negative point. What remains, would be a piece of translated work to be graded and compared to other elements including other translations. This framework is categorized under three possible headings (as cited in Waddington, 2001):

1. Translation mistakes: Inappropriate renderings which affect the understanding of the source text; these are divided into eight categories: contresens, faux sens, nonsens, addition, omission, unresolved extra-linguistic references, loss of meaning, and inappropriate linguistic variation (register, style, dialect, etc.).

2. Translation major errors: Inappropriate renderings which affect expression in the target language; these are divided into five categories: spelling, grammar, lexical items, text and style.

3. Translation minor errors: Inadequate renderings which affect the transmission of either the main function or secondary functions of the source text.

\section{Analysis of the Corpus of English Translations of Product Labels}

The main aim of this research was to reveal the nature of English translation of Persian labels appearing on products such as 'Made in Iran' in addition to any lind of expressive text having an advertisement or commercial nature. In doing so, the investigation began by analyzing the collected English translations of the product labels appeared on the products. At this stage, the corpus of three-hundred translated product labels were analyzed and categorized into three different types including 'grammatical', 'semantic' and 'pragmatic'. The categorization of errors was based on 
the linguistic taxonomy of errors provided by Keshavarz (1993), which was in turn very similar to the taxonomy proposed by Hendrickson (1979). These errors are defined as followings:

1) Grammatical errors: Errors in the use of tenses, prepositions, articles, as well as the wrong use of plural morphemes and parts of speech are considered as examples of grammatical errors (Keshavarz 1993).

2) Semantic errors: This category contains errors of meaning, such as wrong word choices, made-up words, and errors in pronounce reference (Keshavarz 1993).

3) Pragmatic errors: A pragmatic error occurs when the wrong communicative effect is produced. When pragmatic rules are violated, ambiguities are often caused, which lead to misunderstanding and miscommunications (Miremad, 1996).

It is important to note that in some cases, no errors were identified. So, these elements were not put under any erroneous category. After collecting the sufficient data, the results were elaborated and discussed as follows.

\section{Results and Discussion}

Three-hundred labels of Iranian home appliances were analyzed and the errors occurred in these labels were demonstrated. Table 1. shows the number and the type of these errors. Using Keshavarz' (1993) model of error analysis, the results indicated that one-hundred and twenty labels out of three-hundred were erroneous. The name and the nature of these labels are represented in Appendix 1. These errors relate to different hierarchical levels of language, e.g., sentence, phrase, word, etc.

As it was mentioned before, the main aim of the present study was to recognize the nature of the most common errors in Iranian product labels. As shown in Table 1., the grammatical error was the most common type of error in translating home appliances labels. It is important to note that most of these translations were done by Iranian translators due to the economy reasons.In other words, availability factor plays an important role in choosing a translator in order to translate a product's label form Persian into English. Figure 1 illustrates the frequencies of different types of errors in a demographic procedure:

\section{Conclusion}

Table 1. The Statistical and Descriptive Data for the Errors Occurred in the Translation of Product Labels

\begin{tabular}{ccccccc}
\hline $\begin{array}{c}\text { Types of } \\
\text { Errors }\end{array}$ & $\begin{array}{c}\text { Translated } \\
\text { Product Labels }\end{array}$ & $\begin{array}{c}\text { Erroneous } \\
\text { Product Labels }\end{array}$ & $\begin{array}{c}\text { Recognized } \\
\text { Errors }\end{array}$ & $\begin{array}{c}\text { Grammatical } \\
\text { Errors }\end{array}$ & $\begin{array}{c}\text { Semantic } \\
\text { Errors }\end{array}$ & $\begin{array}{c}\text { Pragmatic } \\
\text { Errors }\end{array}$ \\
\hline \multirow{2}{*}{ N of Errors } & 300 & 120 & 220 & 110 & 80 & 30 \\
\hline
\end{tabular}

During the process of translation, some changes must be made. These changes are referred to as translation 'shifts'; the notion which was introduced by Catford (1965) for the first time. There might be a series of reasons for such phenomena, including cultural, linguistic, etc. Only by observing these shifts, a piece of tangible work would be obtained, holding a higher level of readability (ibid.).

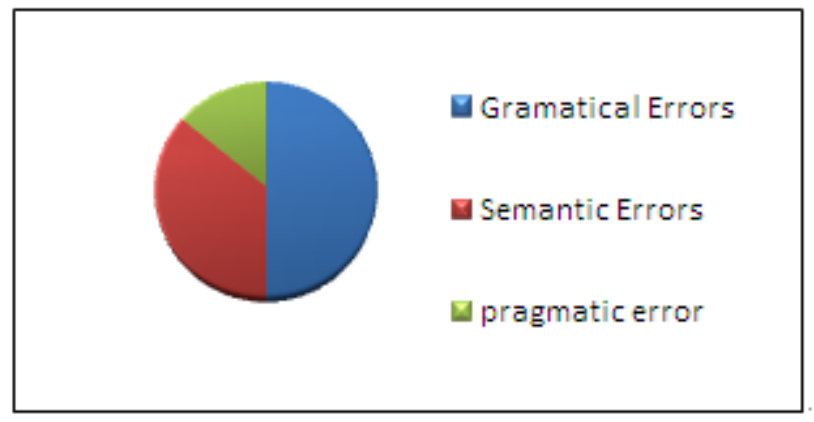

Figure 1. The Frequencies of Different Types of Errors in the Translations of Iranian Home Appliances Products

On the other hand, studying the process, the product and the function of translation has always been an important issue in favor of descriptive translation studies (Holmes, 1988). While dealing with product-oriented descriptive translation studies, the quality of a translated work would be compared in relation to other texts. These texts, as Chesterman (2007) believes, could be classified under the following categories:

a) source texts (in order to show the equivalence relation);

b) non-translated comparable texts in the target language (in order to work on the naturalness relation);

c) other translations (for conducting research on translation universals); or

d) non-native texts.

As the results of the present study showed, there might be a series of problematic issues encountered while daeling with the act of translation from a source text into a target text.As for the present study, grammatical errors were the ones holding the highest frequency among the other types of errors. This could possibly due to the fact that English and Oersian are totally different in many aspects. In other words, the closer the language families, the easier the process of translation would be (Brown, 1994). Knowing all these issues, however, could possibly act as a great deal of help to the translators in order to understand the phenomena of the translation better. 


\section{Appendix 1.}

\section{Sample of the Errors Occurred in the Translations of Iranian Home Appliances}

\begin{tabular}{|c|c|c|}
\hline Product Brand & Elements in Question & Type(s) of Errors Observed \\
\hline \multirow{4}{*}{ (Decopal) } & -practical and functional & Grammatical \\
\hline & -Dishwasher safe & Pragmatic \\
\hline & -Simple and modern & No error \\
\hline & $\begin{array}{l}\text {-This product has been especially tempered for added resistance to } \\
\text { breakage and hot liquid }\end{array}$ & Semantic \\
\hline \multirow[b]{2}{*}{ (Pars blour) } & -with 6 Jars of assorted herbs/spices +rack & No error \\
\hline & $\begin{array}{l}\text {-taking care of your spice rack } \\
\text {-We recommend wiping each spice jar and the spice rack frame before } \\
\text { first use, wipe clean with a damp cloth and dry thoroughly. } \\
\text {-Do not use scourers on this product. Looking after your new heath cotes } \\
\text { product will help you prolong its life and should serve you well for years } \\
\text { to come. }\end{array}$ & No error \\
\hline \multirow{2}{*}{ ( Noritazeh) } & -MINIATOR large plate on foot & No error \\
\hline & -Medium bowl on foot & No error \\
\hline ( Sinjer) & -super gus oven & Grammatical \\
\hline \multirow[b]{2}{*}{ (Segal) } & -super home appliances & No error \\
\hline & $\begin{array}{l}\text {-high quality and exclusive beauty } \\
\text {-security and reflex glasses } \\
\text {-heat resistant glasses } \\
\text {-covered by electrostatic powder color }\end{array}$ & No error \\
\hline \multirow[t]{3}{*}{ (Berkeh) } & -the civilization packs to unload to & Semantic \\
\hline & -Please not to trample to step & Grammatical/Semantic \\
\hline & -the usage invited the detailed reading manual before & Grammatical/Semantic \\
\hline \multirow{3}{*}{ (Snowa) } & $\begin{array}{c}\text {-no.1 in the world } \\
\text {-New experience, magical difference }\end{array}$ & No error \\
\hline & $\begin{array}{c}\text {-buy and save } \\
\text {-Real meaning of eco wash }\end{array}$ & Semantic \\
\hline & -air jet dryer system & No error \\
\hline (Orkideh) & $\begin{array}{l}\text {-vegetable cutter machine } \\
\text {-The best quality }\end{array}$ & No error \\
\hline \multirow{2}{*}{ ( Himalia) } & $\begin{array}{c}\text {-ozone friendly } \\
\text {-Tropical compressor }\end{array}$ & Grammatical/Semantic/Pragmatic \\
\hline & -Fast freeze & No error \\
\hline ( kaveh) & $\begin{array}{l}\text {-Accessories shown in photograph are for display purpose only and not } \\
\text { include in this package }\end{array}$ & Grammatical \\
\hline $\begin{array}{ll}\text { (Pars refrigerator and } \\
\text { freezer) }\end{array}$ & $\begin{array}{c}\text {-8 drawers freezer } \\
\text {-Electronic control system equipped with: } \\
\text { 1.Voltage protector 2.Opening door sound and lighting alarm 3.Smart } \\
\text { defect detection system 4. Economy system 5. Cooling rate display } 6 . \\
\text { Quick freeze system } \\
\text {-Plastic or wire freezer boxes } \\
\text {-Manual defrost } \\
\text {-Anti bacteria door gasket } \\
\text {-Enable to be set with refrigerator (6648) as SBS } \\
\text { - } \text {-Free installation. } \\
\text {-Loading capacity:5 } \\
\text {-Number of programs:14 } \\
\text {-Drum material :stainless steel } \\
\text {-Tub material : enameled steel }\end{array}$ & No error \\
\hline
\end{tabular}




\begin{tabular}{|c|c|c|}
\hline & -Noise (db): $45-50$ & \\
\hline (Adonis heater) & $\begin{array}{c}\text {-Enamel coated inner reservoir } \\
\text {-High heat capacity } \\
\text {-Double fuel options by according to orders } \\
\text {-Guarantee } 30 \text { months } \\
\end{array}$ & No error \\
\hline $\begin{array}{c}\text { (Persia electronic } \\
\text { shaver) }\end{array}$ & $\begin{array}{c}\text {-It does not take more space. } \\
\text {-Changing its blades is easy and quick. } \\
\text {-It has high power for cutting hard materials such as ice. }\end{array}$ & No error \\
\hline \multirow[b]{2}{*}{ (Pars khazar) } & $\begin{array}{c}\text {-Leggy fan } \\
\text {-Motor produced by Pars khazar with Japan technology } \\
\text {-Its height is } 125 \text { and it can be adjust to } 165 \mathrm{~cm} .\end{array}$ & Semantic \\
\hline & $\begin{array}{l}\text {-Metal legs with chromium coat } \\
\text {-Consumption voltage : } 230 \mathrm{v} \\
\text {-It has three speed (low, average, high) } \\
\text {-It has turn off and turn on button } \\
\text {-Easy installation }\end{array}$ & Grammatical \\
\hline (Pars khazar Strainer) & $\begin{array}{c}\text { - Cone roller } \\
\text {-Main bonnet } \\
\text {-Dross vessel } \\
\text {-Turn off and turn on button } \\
\text {-Power of } \\
\text {-Consumption electronic : } 220 \mathrm{w}\end{array}$ & No error \\
\hline (Botan radiator) & $\begin{array}{l}\text {-High thermal power and need to less wing } \\
\text {-High resistance for erosion } \\
\text {-European quality of standard }\end{array}$ & Grammatical \\
\hline \multirow[t]{2}{*}{ (Uranous) } & -To last for years & Grammatical \\
\hline & $\begin{array}{c}\text {-Practical and stylish } \\
\text {-Available in a wide range of colors and decoration } \\
\text {-Our range include } \\
\text {-Food storage } \\
\text {-Waste collection } \\
\text {-Food preparation } \\
\text {-others }\end{array}$ & No error \\
\hline (Sinjer oven) & -closed door grilling system & No error \\
\hline $\begin{array}{l}\text { Snowa } \\
\text { refrigerator(side y } \\
\text { side) }\end{array}$ & $\begin{array}{c}\text {-Nano silver poly technology } \\
\text {-Touch screen LCD } \\
\text {-Smart sensor } \\
\text {-Counter doors } \\
\text {-Titling pockets } \\
\text {-Suitable dispenser height for jar } \\
\text {-Smooth opening door } \\
\text {-Magic cool select zoon }\end{array}$ & No error \\
\hline $\begin{array}{l}\text { (Nicala :Gas space } \\
\text { heater) }\end{array}$ & $\begin{array}{l}\text {-The notable name remains } \\
\text {-High heater } \\
\text {-Low consumption } \\
\text {-Variety of product }\end{array}$ & No error \\
\hline
\end{tabular}

\section{REFERENCES}

[1] Barghout, M. A. M. (1990). Translation quality assessment: An application of a rhetorical model, $\mathrm{PhD}$ thesis, University of Salford, UK.

[2] Brown, H.D.(1994). Teaching by principles: Interactive language teaching methodology. New York: Prentice Hall Regents.

[3] (2000). Principles of language learning and teaching. Englewood Cliffs, NJ: Prentice Hall.

[4] Catford, J. C. (1965). A linguistic theory of translation:An essay on applied linguistics. Oxford: Oxford University
Press.

[5] Chesterman, A. (2007). On the idea of a theory. Across Languages and Cultures, 8 (1),pp. 1-16.

[6] Corder, S. P. (1967). The significance of learner's errors.IRAL, 5, pp.161-170.

[7] (1971). Idiosyncratic dialects and error analysis. IRAL, 2, pp.147-160.

[8] Ellis, R. (1994). The study of second language acquisition. Oxford: Oxford University Press.

[9] Gass, S. \& Selinker, L. (1994). Second language acquisition: An introductory course. Hillsdale, NJ: Erlbaum.

[10] Halliday, M. A. K.(1985). Spoken and written language. Oxford: Oxford University Press. 
[11] Holmes, J. S. (1988). The name and nature of translation studies, In L. Venuti (Ed.) The Translation Studies Reader. (pp.172-185). New York: Routledge.

[12] House, J. (1997) Translation quality assessment: A model revisited, Tübingen: Niemeyer.

[13] Hurtado, A. A. (1995): "La didáctica de la traducción. Evolución y estado actual,"X Perspectivas de la Traducción, (P. Fernández, trans.), Valladolid, Universidad de Valladolid, pp.49-74.

[14] Keshavarz, M. H. (1993). Contrastive analysis and error analysis. Tehran: Rahnama Publication.

[15] Koller, W. (1979/1989). Equivalence in translation theory.In A. Chesterman (Ed.), Readings in translation theory(pp. 99-104). Helsinki: OyFinnLectura Ab.

[16] Lado, R. (1964). Language teaching: A scientific approach. New York:McGraw-Hill.
[17] Miremadi. A. (1991). Theories of translation and interpretation. Tehran:SAMT.

[18] Munday, J. (2008). Introducing translation studies: Theories and applications (2nd Ed.). London: Routledge.

[19] Nord, C. (1991): Scopos, loyalty and translational conventions. Target, 3 (1), pp. 91-109.

[20] Scriven, M. (1993). Hard-won lessons in program evaluation. San Francisco: Fossey-Blass.

[21] Selinker, L.(1972). Inter-language. IRAL, 10(3),pp. 219-243.

[22] Waddington, C. (2001). Different methods of evaluating student translations: The question of validity. Eurodite, 46(2), pp. 311-325.

[23] Williams, M. (2005). Translation quality assessment: An argumentation-centred approach. Ottawa: University of Ottawa Press. 